\title{
TITLE:
}

\section{THE "CNIDOBLAST" AS AN EXCITABLE SYSTEM}

$\operatorname{AUTHOR}(\mathrm{S}):$

Yanagita, Tame-Masa

\section{CITATION:}

Yanagita, Tame-Masa. THE "CNIDOBLAST" AS AN EXCITABLE SYSTEM. PUBLICATIONS OF THE SETO MARINE BIOLOGICAL LABORATORY 1973, 20: 675-693

ISSUE DATE:

1973-12-19

URL:

http://hdl.handle.net/2433/175751

RIGHT: 


\title{
THE "CNIDOBLAST" AS AN EXCITABLE SYSTEM
}

\author{
Tame Masa YANAGiTA \\ Department of Biology, Ochanomizu University, Tokyo, and \\ Tateyama Marine Laboratory, Tateyama, Chiba Prefecture
}

With 10 Text-figures

\begin{abstract}
It seems established by now that nettling response as it is given normally by cnidarian nematocysts belongs to a rather standard type of physiological excitation event, though there is still some question about the functional significance of the morphological "cnidoblasts". It is instructive to consider this subject in comparison with that of muscle contraction response provided that one adopts the view of "post-energization' rather than that of "pre-energization". One of the centers of interest is at present in identification of coupler agent that mediates between the external excitation event and internal explosion event. For this problem, the experimentation with isolated nematocysts are of critical role. It was shown that apparently inconsistent situations are to be found even among the same type of cnida from closely related species, and it is interesting to see how one can negotiate such diversions to bring them into fundamental uniformity. Efforts so far made revealed us that there is still need for studying somewhat intricated interrelationship between, water, anions, and cations as to triggering of the isolated cnidae. Such study may lead to an understanding of the mode of operation of cnidae in situ in the normal response system. The discussion extends further to include the problem of remote control of nematocyst discharge.
\end{abstract}

A very comprehensive "Review of researches on nematocysts" covering "Development and migration" through "The significance in classification and phylogeny" has been presented by PICKEN and SKAER (1966) in the 1965 symposium on cnidarian biology held in London. Thanks to this contribution, though being now of several years ago, the present paper may be allowed to limit itself to the subjects directly related to the physiological mechanism of cnida discharge.

\section{Determinism and Mechanism of Discharge}

In consideration of this subject, two major groups of findings may provide certain clues at our starting. (1) The discharge of nematocysts, in its natural form of occurrence in response to a "contact-chemical" stimulation (PANTIN, 1942) by the prey, belongs apparently to the excitation events in the sense which is usual among physiologists, in that similar one can be induced artificially by passing an electric current through the cnida-bearing surface (Fig. 1) or by adding $\mathrm{K}^{+}$ions to the external medium, and can be inhibited reversibly with $\mathrm{Mg}^{2+}$ ions and other agents that are usually referred to as anaesthetics (YANAGITA, 1960; BLANQUET, 1970). (2) The nematocysts 
can be isolated by some means from the cnidarian tissue and preserved so as to retain the capacity of exploding (discharging) when an appropriate agent is applied to them. Such agents are quite distinct from those which are effective in inducing the event 1 (YANAGITA, 1959a; Blanquet, 1970).

We owe the terminology, déterminisme (related to the event 1) versus mécanisme (related to the event 2) of nematocyst discharge to WeILL (1934), for making distinction between the problems proposed by these two aspects of the response.

An analogous situation is found to be established in the case of contracting muscle cells. Muscle contraction is a typical excitation event with its own determinism and, at the same time, one can isolate or extract the lifeless acto-myosin organelles in filament form, furnished with its own mechanism, and store these indefinitely to make contract at any time with ATP and other agents applied on it; the so-called mechanochemical system in isolation.

Only in the case of nematocysts, there are much more elaborate structural components visible under light microscope, and even still more under present-day electron microscope, say, cnidocil and operculum, as well as the classical "lasso" of EwaLD, the recent "supportive rods" of WestFall (1970) (Fig. 2), and so on. For further examples of recent contributions in this field, see MatTern, Park, and Daniel (1965), WestFall (1965), and SlautTerback (1967). In the present symposium also, good many interesting pictures have been presented by RoBSON (1973). Such a situation is apt to divert the imaginative mind of observers in various ways, as it was just the case in past in the golden age of light microscope. But it may be important to remember the fact that the mechanism of nematocyst as well as of muscle contractile system can be triggered with a mere contact of the denuded organelle in vitro with rather common and gentle kinds of chemical agents in solution, and does not demand such a specific mechanical agent as might have been required for a task of pulling the cnidocil, lifting the operculum, and so on. With this regard also, we can deal with determinism and mechanism of the nematocyst discharge in the same way as with those of muscle contraction.

\section{The Problem of "Cnidoblasts"}

Before proceeding further the old problem for the present writer about "cnidoblasts" (YANAGITA, 1959b; YANAGITA and WADA, 1959) will be taken up first in a renewed version. A cnidoblast is known as a nucleated cell that secretes the nematocyst internally as a "metaplasmic" organelle and houses this until the moment of discharge evocation. Actually, we can see such a cell surrounding the penetrants of freshwater hydra that have been isolated from the tentacles with some gentle means (cf. Fig. 3). Also in the case of acontium of sea anemone, electron micrographs furnished by WestFall (1965) as well as by the present writer (with Nozomu SAITo, unpublished) showed cell figures, furnished distally with a coronet of microvilli (or "stereocilia") 


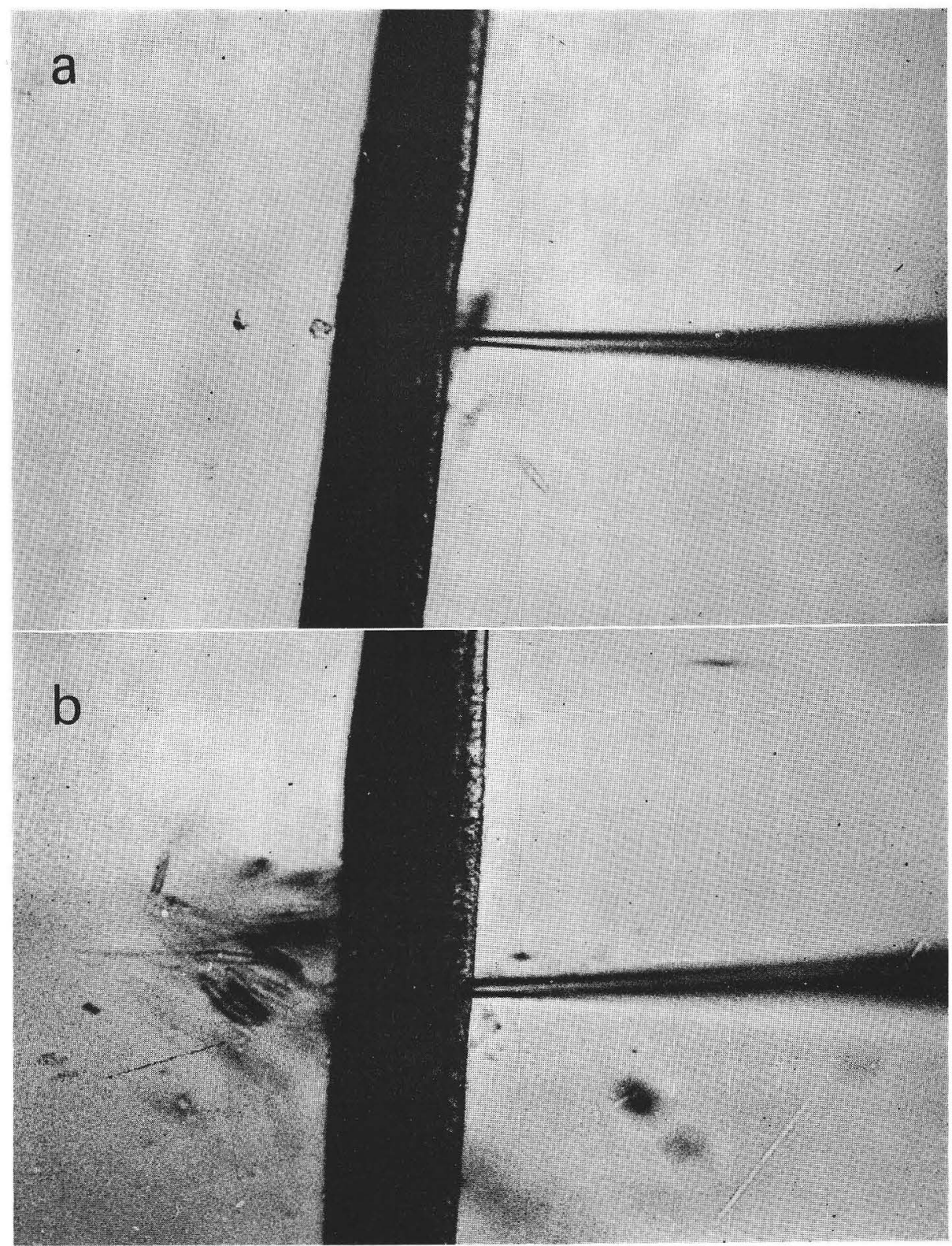

Fig. 1. Electric excitation of cnidoblasts in an acontium of Haliplanella luciae with glass electrode ( $\mathrm{KCl}-\mathrm{AgCl}-\mathrm{Ag}$ ) about $10 \mu \mathrm{m}$ in tip diameter. A single make or break shock from induction coil was effective in accordance with the polar excitation law. The acontium lies with its armed side toward left in the pictures before (a) and after (b) the shock. (YANAGITA and SEKI, unpublished). 
encircling a flagellum, each enclosing the nematocyst as it appears (Fig. 4). All these are morphological findings. Functionally, however, it is uncertain whether such a mother cell ("Plasmamantel" of classical authors) plays actually some role in the determinism of discharge. The excitable surface membrane which is assumed to be interposed between the exterior and the cnida inside may not necessarily be ascribed to this cell, for the "cnidoblast" itself is embedded in an epithelial layer, or, in the case of hydra tentacles, in a large battery cell (Fig. 5) (see further SLauTTERBaCK, 1967; WESTFALL, 1970.) Neighboring epithelial cells or enclosing battery cell could possibly offer their own surface membranes as the physiological (bioelectric) trigger device for

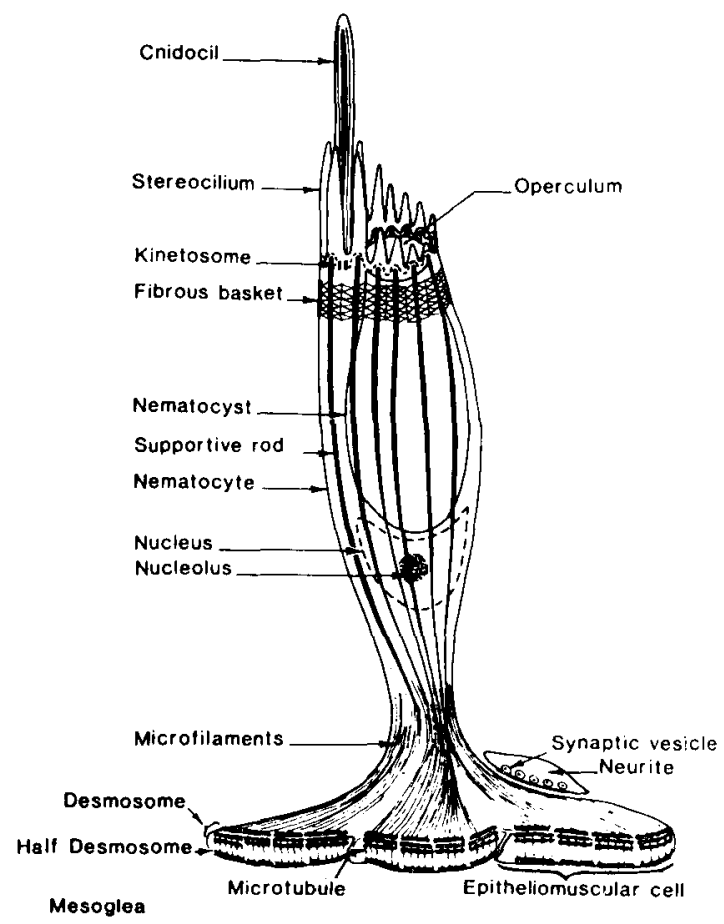

Fig. 2. Diagram of a cnidoblast from a tentacle of Gonionemus as based on electron micrographs. Note the indication of a synapse in addition to the various accessory equipments in the cnidoblast. (From WestFall, 1970).

the cnidae within. Besides, it is a general impression from the micrographs that the cnidoblasts are cells rather loosened in cytoplasmic consistency and usually occupied by large vacuoles especially toward the proximal half. It may well be that they are already near-ghosts that serve merely as less important envelopes for the cnidae.

There is not yet any discharge experiment done systematically with isolated cnidoblast cells. When unexploded nematocysts are liberated through extrusion response in an salt-free medium (e.g., $1 \mathrm{M}$ glycerol solution) from the acontium of Haliplanella (or Diadumene) luciae, the capsules are already denuded without any 
remain of a surrounding cell (YANAGITA, 1959b; BLANQUET, 1968). In the case of hydra penetrants, which are isolated with their cnidoblasts still remaining around them, $\mathrm{K}^{+}$ ions and electric current could not be found to be effective in evoking discharge (YANAGITA, 1969) unlike in the case of nematocysts in situ in tentacles. On the other hand, $\mathrm{Cl}^{-}$and other anions in sufficient concentration are found to evoke explosion in such cnidoblasts. At least in such a state the "cnidoblasts" of penetrants must have already been invalidated functionally.

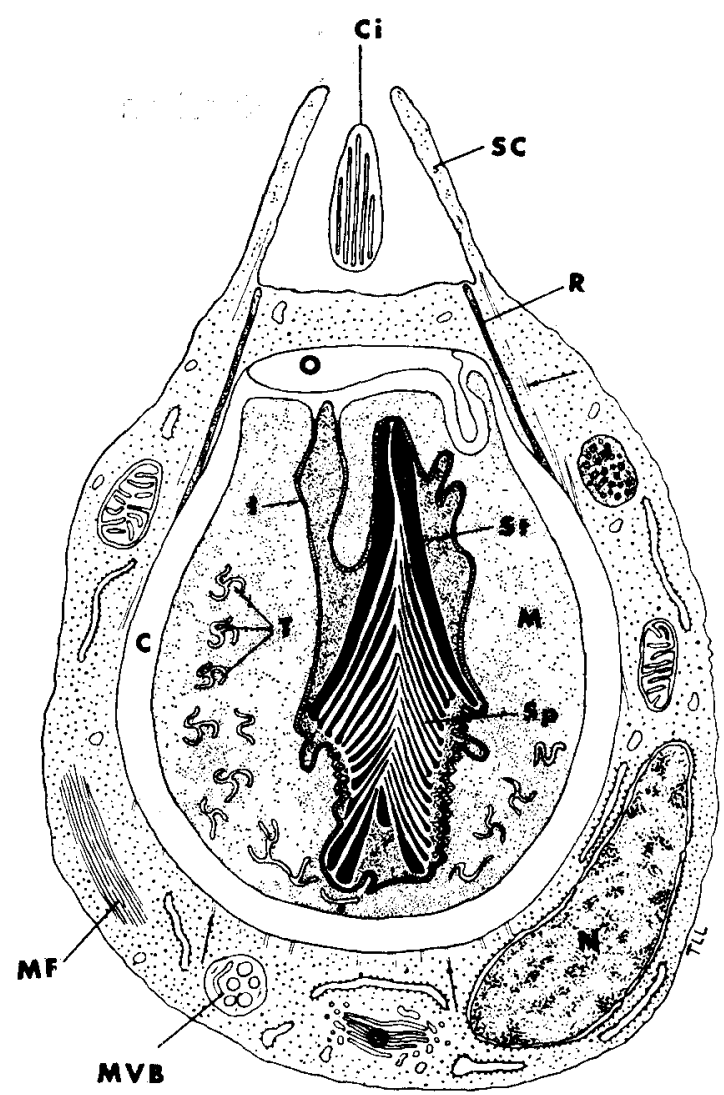

Fig. 3. Diagram of a Hydra cnidoblast containing a stenotele as based on electron micrographs. C, capsule; Ci, central cilium; G, Golgi apparatus; I, invaginated capsular wall; M, matrix; MF, myofilaments; MVB, multivesicular body; N, nucleus; $\mathrm{O}$, operculum; R, supporting rods of cnidoblast; Sc, supporting rods of cnidocil; St, stylet; T, thread. (From LenTZ, 1966).

All this is the reason why the present writer chooses still for the moment to put quotation marks to the term "cnidoblast" in discussing a subject related to explosion determinism. The term is used here to represent the physiological unit of response rather than the cnidoblast cell as a morphological entity. 
It may not be a very hard task for a veteran electrophysiologist to insert a recording microelectrode into the cnidoblast cell to pick up a membrane potential, if any. As for the present writer, we are trying still now to lead off some electric potential from a microelectrode inserted rather blindly into the interior of acontial tissue (filament diameter: about $120 \mu \mathrm{m}$ ). This trial has given as yet only a negative result. It has not yet succeeded to detect a potential difference between inside and outside the acontium, even with the external medium changed in various ways from normal sea

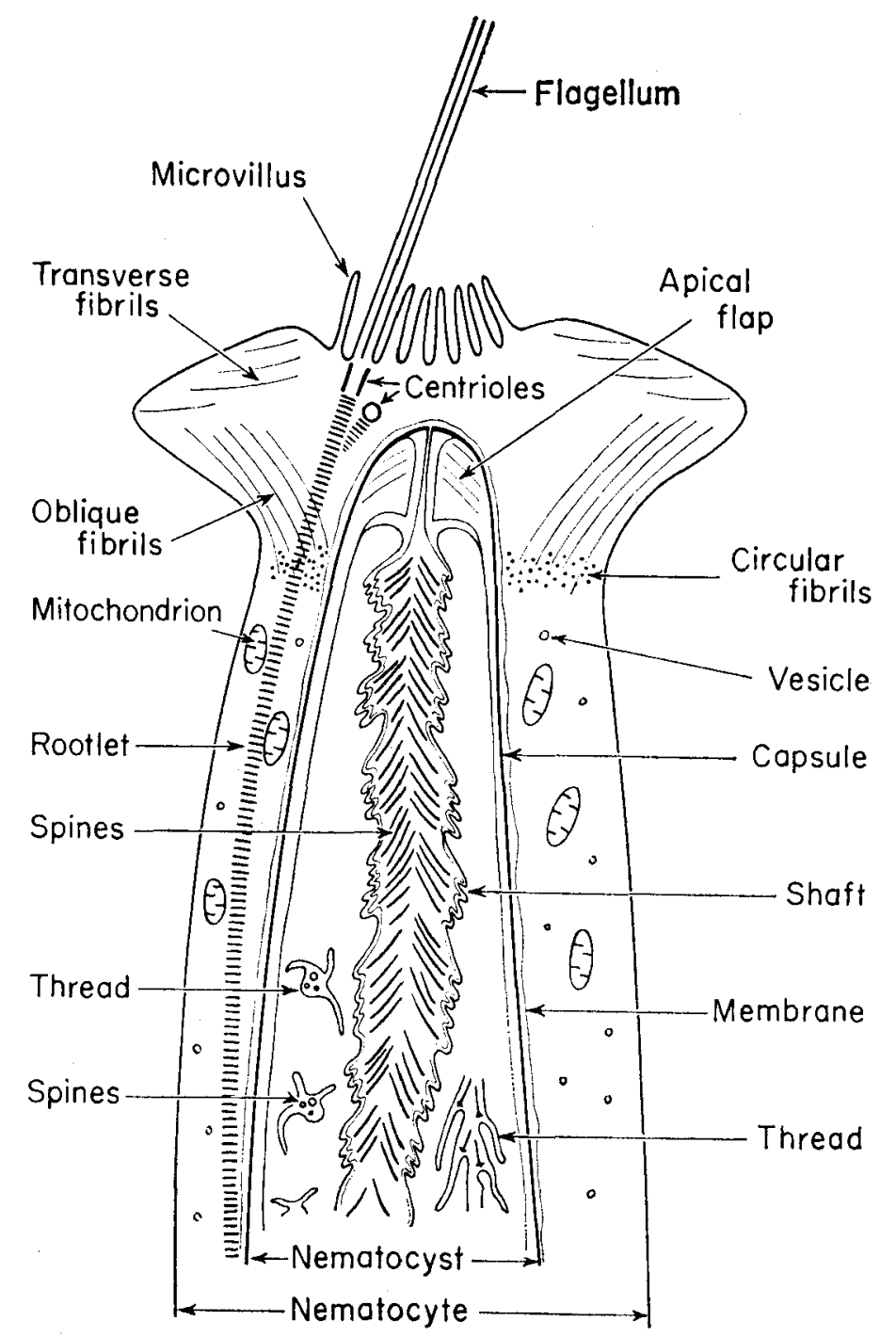

Fig. 4. Diagram of a cnidoblast containing a microbasic b-mastigophore from a Metridium acontium, as based on electron micrographs. (From WestFall, 1965). 


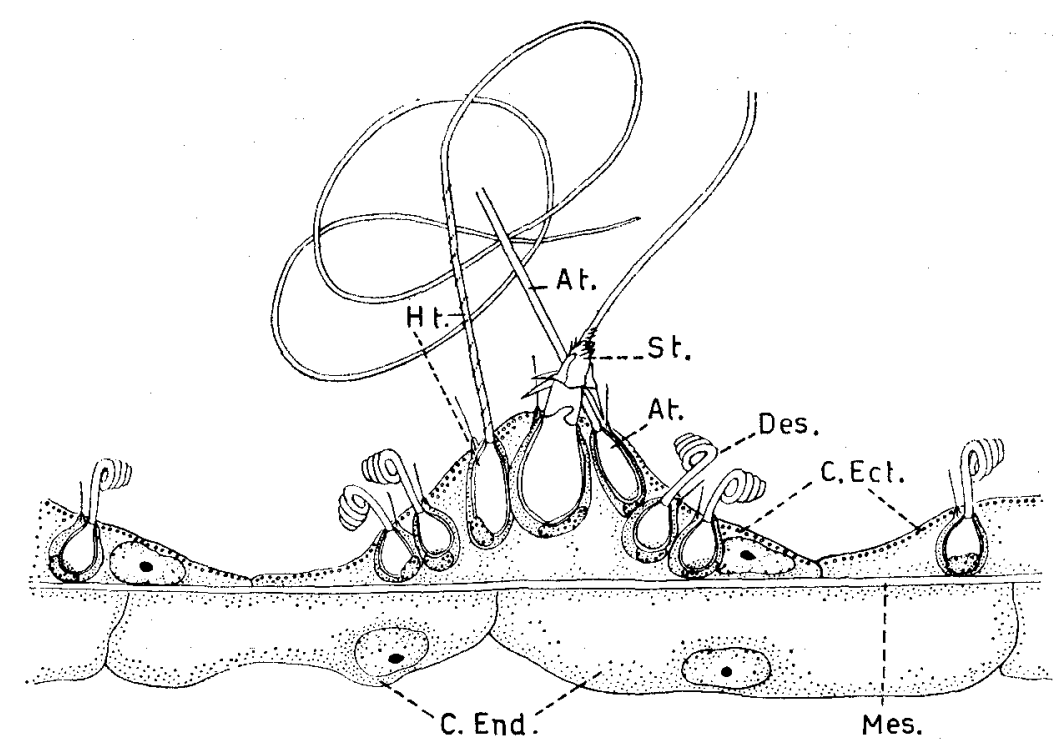

Fig. 5. Diagram of a battery cell of the Hydra tentacle. At, atrich; C. Ect, ectodermal cell; C. End, endodermal cell; Des, desmonene; Ht, holotrich; Mes, mesoglea. (From BRIEN, 1961).

water. ${ }^{1)}$ On the other hand, osmotic behavior of a cut piece of acontium was found to be of a rather standard type, osmotic swelling and shrinkage taking place rapidly (complete in some one minute) and reversibly (YANAGITA, 1972). Our next attempt that is going on at present is to determine the electric resistance across the surface layer of acontium to learn something more about the physical make-up of the same.

\section{Identification of the Coupler Agents}

In making a comparison between the determinism of muscle contraction and that of cnida discharge, the problem now is to find the very counterpart in the latter of intracellular $\mathrm{Ca}^{2+}$ ions in the case of muscle; that is to say, the identification of the coupler agent that works in between the surface event of excitation and the inner event of nettling thread eversion. One might speak of excitation-explosion coupling as against excitation-contraction coupling. This agent should literally couple the determinism with mechanism. The present writer was somewhat optimistic when he attributed this role of intracellular transmission to the $\mathrm{Cl}^{2+}$ ions from the external medium of sea water in the case of microbasic p-mastigophores of acontium of Haliplanella luciae (YANAGITA, 1959b; 1960). He had long been in the belief that natural sea water was not a very inappropriate bathing medium for keeping isolated

1) See the appendix to this paper. 
cnidae for experimental use. But a youngster who was assisting the writer at that time insisted that the nematocysts were discharged in sea water to such an extent as was not to be set aside as some accidental occurrence. Thus we were finally lead to confirmation of effect of sea water (and of $0.5 \mathrm{M} \mathrm{NaCl}, \mathrm{KCl}$, and so on) in evoking discharge of isolated cnidae up to $100 \%$ in the optimal conditions. Choline chloride and the like were found to have the same effect, while some $\mathrm{Na}$ salts such as $\mathrm{Na}_{2} \mathrm{SO}_{4}$ were without effect, so that $\mathrm{Cl}^{-}$was concluded to be the active moiety. Then it was necessary for completing the story only to assume entry of $\mathrm{Cl}^{-}$ions from the exterior into the tissue ("cnidoblasts") in the moment of excitation, say, due to an increase in the surface permeability for this ionic species. Excitation experiments with acontia bathed in $\mathrm{Cl}^{-}$-poor media also supported this hypothesis (Fig. 6).

It should be admitted, however, that $\mathrm{Cl}^{-}$was not the only ion species that was

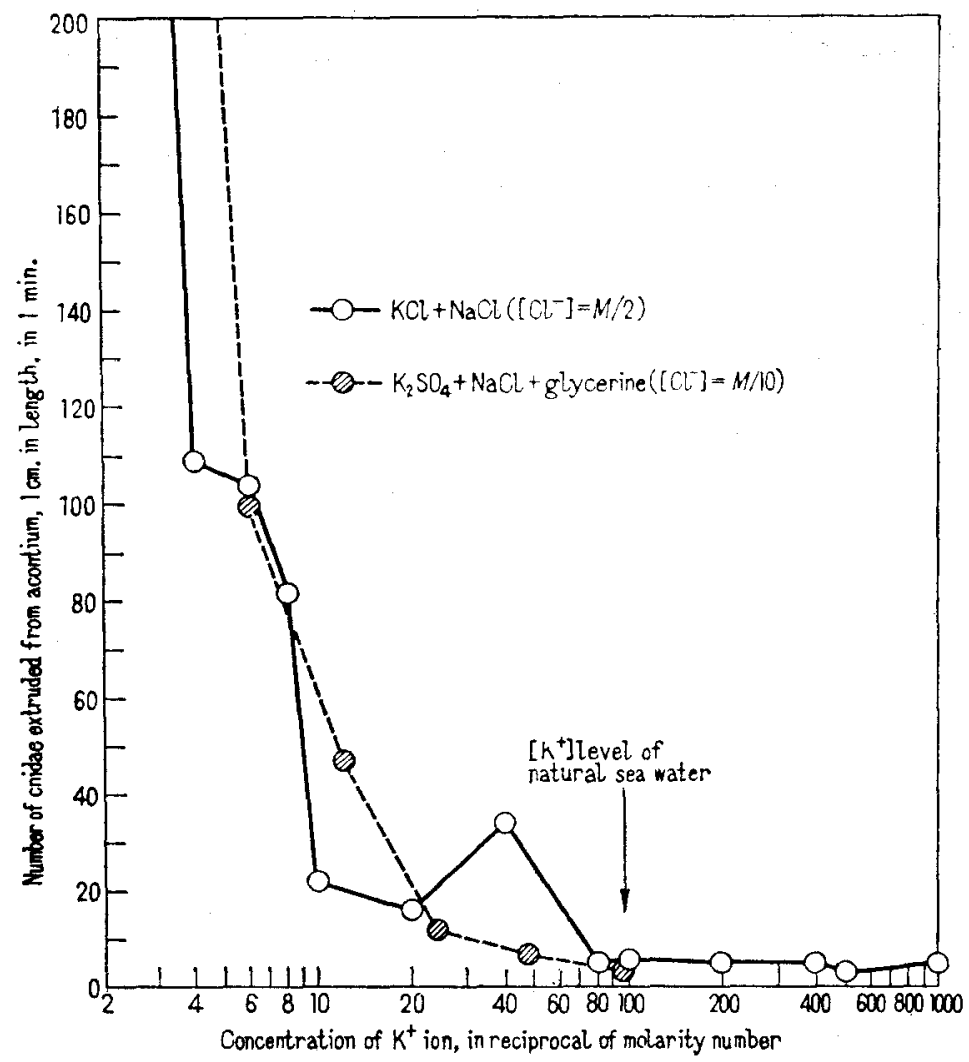

Fig. 6. An experimental result to demonstrate the "cnidoblast"-exciting effect of $\mathrm{K}^{+}$ions and the nematocyst-triggering effect of $\mathrm{Cl}^{-}$ions. In the $\mathrm{Cl}^{-}$-poor medium (dots) $\mathrm{K}^{+}$ions induced only extrusion of nematocysts most of which remained unexploded, whereas $\mathrm{K}^{+}$ in the $\mathrm{Cl}^{-}$-rich medium (circles) elicited normal eversion of threads (not represented in the graph). (From YanaGiTA, 1960). 
capable of triggering the isolated cnidae. Actually, a whole series of univalent anions with some exceptions such as $\mathrm{SO}_{4}{ }^{2-}$, as well as some plurivalent ones, were found to have the same effect (YANAGITA, 1959a). Therefore, any of these ions had qualification for the coupler role if it was available in a sufficient concentration; only $\mathrm{Cl}^{-}$had been the ionic species that would be most amply available among them for cnidae of a sea anemone. Again, the coupler agent was not necessarily to be derived from the exterior, but might well be installed in the interior like in the case of muscle cells.

In the case of freshwater hydra, as a matter of fact, one could never expect for such a coupler role played by an external ion, because hydra can nettle even in distilled water. A coupler agent, if any, had to be supposed to exist in the "cnidoblast" interior. Though it was found experimentally that $\mathrm{Cl}^{-}$ions were effective in evoking discharge of isolated stenoteles in a strength of $50 \mathrm{mM}$, it was very unlikely that they were playing this role in the "cnidoblasts". One of the possibilities among the ions which were found to induce experimentally the discharge of isolated stenoteles (and of the three other types from hydra's cnidome) was secondary phosphate. Tests with a rather limited number of $\mathrm{Na}$ and $\mathrm{K}$ salts showed that $\mathrm{HPO}_{4}{ }^{2-}$ ions at $30 \mathrm{mM}$ were effective in evoking discharge of the cnidae that had been liberated by means of gentle sonication, while $\mathrm{H}_{2} \mathrm{PO}_{4}{ }^{-}$ions were without effect (Yanagita, 1969). Thus the present writer discussed in the 1968 symposium on coelenterate biology held at the Asamushi Marine Station as follows: ". . . , for instance, if there is intracellular release (instead of intrusion from exterior) of a sufficient amount of anions, say, $\mathrm{HPO}_{4}{ }^{2-}$, in the cytoplasm at the distal ("stoppered") end of cnida capsule in the moment of excitation, it would be just logical inference from the above results that it must lead necessarily to explosion of that cnida [provided there was no particular inhibitory factor present]." (YanAGITA, 1969.)

It is interesting to note in this connection that, according to LENTZ and BARRNETT (1961), there is localized distribution of a number of phosphatases to be detected cytochemically in the said region of hydra cnidoblasts, and, further, that external application of substrate and inhibitor substances for the phosphatase activities to the tentacle causes sensitization and desensitization, respectively, of the cnida response system toward a tactile stimulus from the exterior (LENTZ and BARRNETT, 1962). (See Table 1 of LenTz, 1966.)

\section{Some Recent Additions to Comparative Studies of Determinism and Mechanism of Discharge}

Since there seems to be a rather wide variation among the kinds both of cnidae and of animals in the details of determinism as well as mechanism of discharging response, it is important at present to do a broad survey over the different kinds of cnidarian material. This may lead eventually to understanding of the underlying uniformity. Let the writer present here three recent examples to this effect. 
(1) Microbasic Mastigophores in the Acontium of Aiptasia palllida

In the first place, recent studies by Richard BLANQUET (1970) with microbasic mastigophores of the acontia of Aiptasia pallida will be presented for discussion. These are material quite close both in the Linnean and in the Weillian systems to the present writer's good old material from Haliplanella (or Aiptasiomorpha, the name suggested by Cutress in personal communication), so that it is interesting to summarize his overall results, as rearranged, in comparison with those with Haliplanella,

Table 1. A comparative summary of responsiveness of isolated mastigophores found with Aiptasia and Haliplanella.

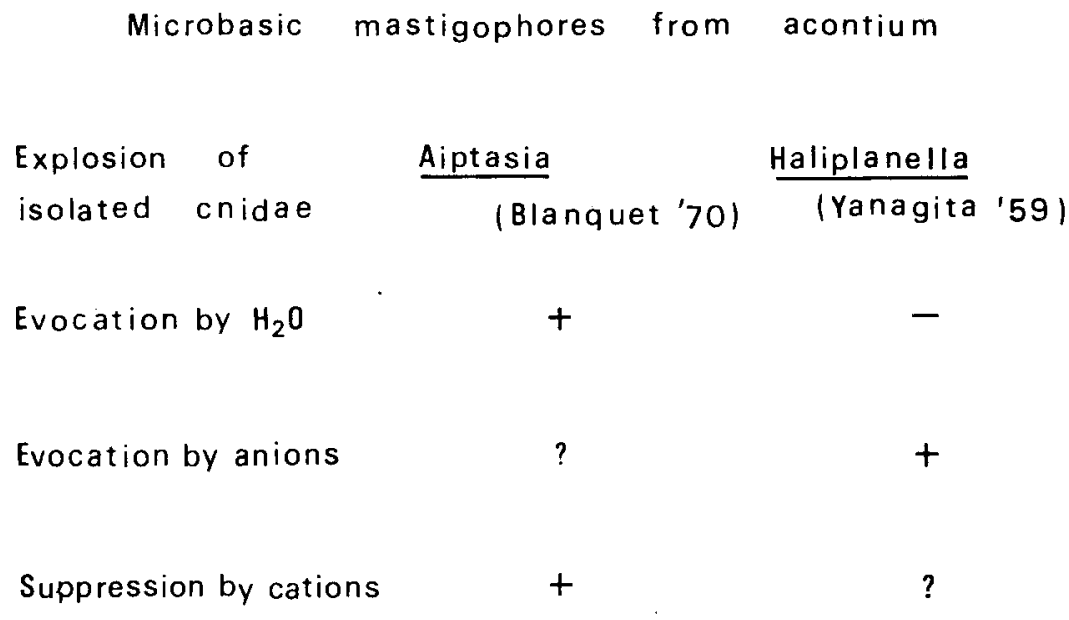

as in Table 1. As to the agents that act from the exterior of acontium to evoke cnida explosion, there are no differences between the two cases. Electric current and $\mathrm{K}^{+}$ ions were both effective, while $\mathrm{Mg}^{2+}$ ions suppress these effects reversibly. However, as will be seen from the table, the two cases are diagonally different from each other as to each of the items tabulated to describe the efficacy in evoking or suppressing the explosion of isolated cnidae. Suppressing effect observed at higher concentrations of neutral salts on Aiptasia cnidae is referred to by BLANQUET as "osmotic effect", though the author is rather negative about a possible coupler role played by an osmotic effect. However, the ineffectiveness of $1 \mathrm{M}$ glycerol in suppressing the explosion seems to indicate that the effect in question is actually to be ascribed to the presence of electrolytes, and particularly to the cation moiety of these as is apparent on inspection of BLANQUET's data. This may make recall the "desensitizing effect" of electrolytes in strength subliminal for explosion, which was found with the cnidae isolated from Haliplanella acontia (YANAGITA, 1959a).

Such differences between Aiptasia and Haliplanella also demand certain alteration 
as to the technique for isolating cnidae with the use of extrusion response. In Aiptasia also, when one immerses its acontium in $1 \mathrm{M}$ glycerol solution, there takes place extrusion of unexploded capsules from the surface, but it is followed here soon by explosion amounting to some $50 \%$ of the extruded cnidae conceivably due to the latter's sensitivity toward $\mathrm{H}_{2} \mathrm{O}$ remaining unsuppressed by any cation (see Table 1). Therefore it was impossible for BLANQUET to use this solution as the isolation medium unlike in the case of Haliplanella. Instead, he tried Na-citrate solution as strong as $1 \mathrm{M}$ and succeeded to obtain a nice preparation of isolated cnidae. These cnidae, however, are apparently still more sensitized toward $\mathrm{H}_{2} \mathrm{O}$ through removal by citrate of $\mathrm{Ca}^{2+}$ ions from the capsules (or specifically from the "stoppers"), so that they explode in distilled water as well as in $1 \mathrm{M}$ glycerol solution, up to nearly $100 \%$, quite in contrast to Haliplanella cnidae, for which both of these are the best media for preserving isolated cnidae in unexploded state.

In relation to the mechanism of triggering the explosion in isolated cnidae, then, it would be interesting to inquire into the question of whether the mastigophores extruded from Haliplanella acontia into glycerol solution (or deionized water) come to correspond in behavior to those from Aiptasia in Na-citrate, provided they get sensitized toward $\mathrm{H}_{2} \mathrm{O}$ by Na-citrate treatment. Some preliminary tests performed lately indicated that this was the case to some extent (YANAGITA and SEKI, 1973a). Na-citrate had been known to evoke explosion of glycerol-isolated cnidae of Haliplanella at lower concentrations owing to the effectiveness of its anionic moiety (YANAGITA, 1959a), but a concentration as high as $1 \mathrm{M}$ was found anew to suppress somehow the reaction also in this material. ${ }^{2)}$ Such "citrated" and still resting cnidae were found to explode when placed in deionized water or in $1 \mathrm{M}$ glycerol solution up to an amount of nearly $90 \%$ though taking a fairly long time $(50 \%$ period: about ten minutes). Explosion tests of the citrated cnidae of Haliplanella with sea water and with $\mathrm{NaCl}$ solution isotonic to the same, however, gave somewhat ambiguous results (10-30\% explosion) both with and without pretreatment with $\mathrm{CaCl}_{2}(0.05 \mathrm{M})$. Thus, nothing can be said as yet about the reversibility of the effect of citrate treatment through re-supply of $\mathrm{Ca}^{2+}$ ions in this material. ${ }^{3)}$

\section{(2) Microbasic Mastigophores in the Nematothecae of Aglaophenia whiteleggei}

The present writer would like to add two little pieces of observation which he and his collaborater had opportunity to make in this summer at the Tateyama Marine Laboratory. One of the material was the large, strong microbasic mastigophores of nematophores of a plumularian hydroid, Aglaophenia whiteleggei. The other was

2) $1 \mathrm{M} \mathrm{Na-citrate} \mathrm{solution} \mathrm{was} \mathrm{found} \mathrm{to} \mathrm{be} \mathrm{an} \mathrm{extrusion-inducing} \mathrm{medium} \mathrm{also} \mathrm{with} \mathrm{Haliplanella}$ acontium, as could be expected from the former results of the writer (YANAGITA, 1959b), eliciting practically no explosion of the nematocysts thus extruded, somehow in this very high concentration.

3) After the treatment with $0.05 \mathrm{M} \mathrm{CaCl}_{2}$ solution for ten minutes the citrated nematocysts were shown to be almost nonresponsive once more toward pure water (explosion less than $10 \%$ ). 
microbasic euryteles on tentacles of a cubomedusan (or cubozoan according to WERNER 1973) jellyfish, Charybdea rastonii (box jelly or sea wasp). The first description of the latter cnidae in that species was made by UCHIDA in 1929 (UCHIDA, 1929). Both animals are rather heavy nettlers for human divers and bathers.

With the cnidae of Aglaophenia nematophores, the writer had been anxious to learn whether they do respond to electric stimulation or not, because it could be suspected from the appearance that they were contained in the nematotheca in a state already denuded of the living matrix of nematophore, which is a kind of dactylozooid. In any way microscopic images were ambiguous in answering this question (Fig. 7a,b). Trials of stimulation using an $\mathrm{Ag}-\mathrm{AgCl}$ electrode (about $150 \mu \mathrm{m}$ in
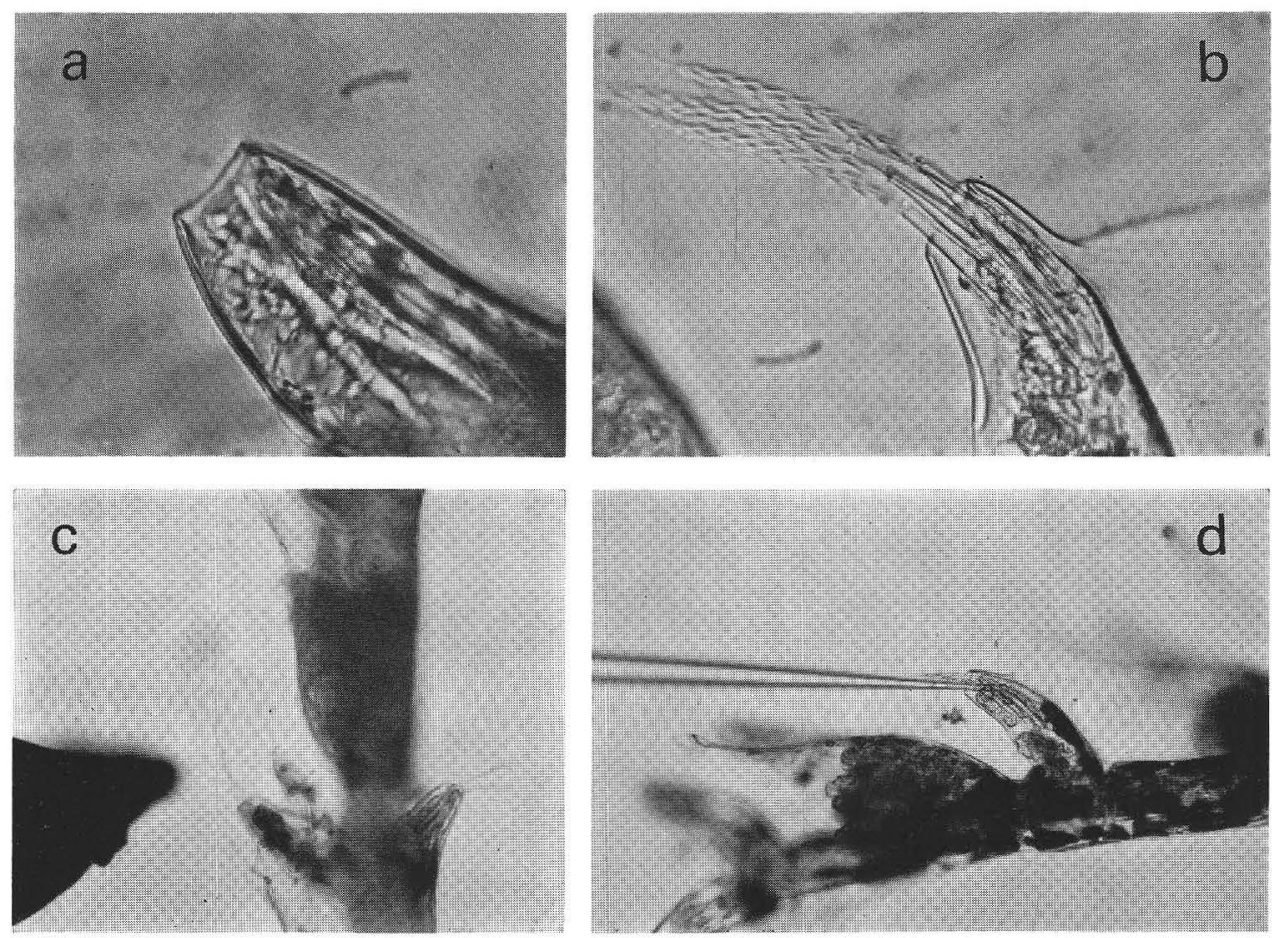

Fig. 7. Nematophores of Aglaophenia whiteleggei before (a) and after (b) discharge, in a greater magnification. (c) Direct stimulation of a nematophore with faradic shocks sent through an electrode. (d) Microinjection of $\mathrm{KCl}$ solution into a nematophore with the result of activation of nematocysts. The nematophore opening is about $10 \mu \mathrm{m}$ in diameter. (From Yanagita and SekI, 1973b.)

diameter) with faradic shocks from induction coil were repeated, and turned out with positive results (Fig. 7c). The cnidae responded to the current with instant explosion, indicating that they are still somehow embedded beneath some excitable surface, as Hyman (1940) had already implied in her description. Micro-injection with a micropipette $5-7 \mu \mathrm{m}$ in caliber of $0.54 \mathrm{M} \mathrm{KCl}$ solution into the opening (about $10 \mu \mathrm{m}$ in 
diameter) of nematothecae was also attempted (Fig. 7d) and proved effective in evoking discharge, too. (Yanagita and SeKi, 1973b). Any further inquiry into this material, say, concerning capsule extrusion or behavior of isolated cnidae, has not been made by this season.

\section{(3) Microbasic Euryteles on the Tentacles of Charybdea rastonii}

The tentacular cnidae of the sea wasp happened to offer the writer and his collaborator a novel problem (YANAGITA and SEKI, 1973c). They responded to electric stimulation, but did not do so to excess external $\mathrm{K}^{+}$ions. Instead, they showed marked explosion response to $\mathrm{Ca}^{2+}$ ions (isotonic $\mathrm{CaCl}_{2}$ solution added to the normal sea water medium). The explosion tended to take place in bursts, each of which was apparently synchronized with an additional contraction in the tentacle. Another finding was the possibility to obtain isolated cnidae in quantity by immersing the tentacle piece in isotonic $\mathrm{KCl}$ solution, in which cnidae did not discharge as mentioned above, but came extruded from the tentacle surfaces, though taking a fairly long time (about twenty minutes). One may recall here the situation that extrusion of unexploded cnidae from Haliplanella acontium takes place in a $\mathrm{K}^{+}$-rich medium (such as $\mathrm{K}_{2} \mathrm{SO}_{4}$, see Fig. 6) as well as in a $\mathrm{Cl}^{-}$-poor medium (such as $1 \mathrm{M}$ glycerol) and is supposed to represent a form of excitation event not much different from the normal nettling response (Yanagita, 1959b). The cnidae liberated into $\mathrm{KCl}$ solution from the Charybdea tentacle did not explode when the medium was changed to deionized water or to isotonic $\mathrm{CaCl}_{2}$ solution, but did so in an amount up to nearly $100 \%$ in a strong $\mathrm{NaOH}$ solution. This indicates that $\mathrm{Ca}^{2+}$ ions are effective only through mediation of the living matrix or "cnidoblasts".

On the other hand, immersion in $\mathrm{Ca}^{2+}$-free sea water made the tentacle somewhat relaxed mechanically and, at the same time, insensitive to electric current as well as to contact with a human hair root, which is a classical tool of nematocyst physiology since PANTIN (1942) and would induce localized discharge and clinging of cnidae from tentacles bathed in normal sea water. This suggests that $\mathrm{Ca}^{2+}$ ions play some role in the determinism of normal response in this case unlike $\mathrm{K}^{+}$ions, which are supposed to induce only artificially the electric depolarization of the membrane. As to the determinism of discharge also, we have to admit that there is some diversity from case to case such as already seen above as to the mechanism of discharge of isolated cnidae.

\section{The Problem of Energetics}

As has already been stated, mere contact of some chemical agents on the isolated organelles suffices to cause these to react, and, at least in the case of nematocysts, they must not necessarily include an energy-rich organic compound such as ATP. This already indicates that there is no need of energization of the system for being activated. 
Energy must be previously stored or built in in the structure and only a triggering signal is wanted. The possibility that such energization is done also in the inverted tube besides the capsule proper was suggested by PICKEN (1953) at first on the basis of an elaborate light microscopic study on Corynactis holotrichs, but a later e.m. study by PICKEN and SKAER (1966) reversed that suggestion into an answer to the contrary.

If one has a sight of the cnidae or cnidoblasts with all their elaborate accessory structural elements, it is somehow tempting to imagine some active process of energization taking place at the very moment of explosion, such as involves ATP or the like (see LENTZ, 1966, pp. 120, 177). Also the conventional point of view in the field of muscle contraction researches may tend to help a preoccupation to arise here. ATP, however, if ever used in the present system, must be used just in the process of cnidogenesis, in which energy is built into the mechanical system of cnida inside the cnidoblast. And it is to be pointed out further that such an understanding of the nature of cnida's mechanism could even feed back a suggestion to the understanding of the very mechanism of muscle contraction.

Current textbooks of general physiology teach that there are two major views opposed to each other as to this question in muscle physiology (e.g., see MAJima, 1969, p. 63). Pre-energization view advocated by A. V. HiLl (based on muscle heat) versus post-energization view proposed by Albert SZENT-GYöRGYI (based on thermodynamics of protein chain molecules). Pre-energization view, which seems to be the most popular, or at least conventional, assumes that, on excitation of a muscle cell,
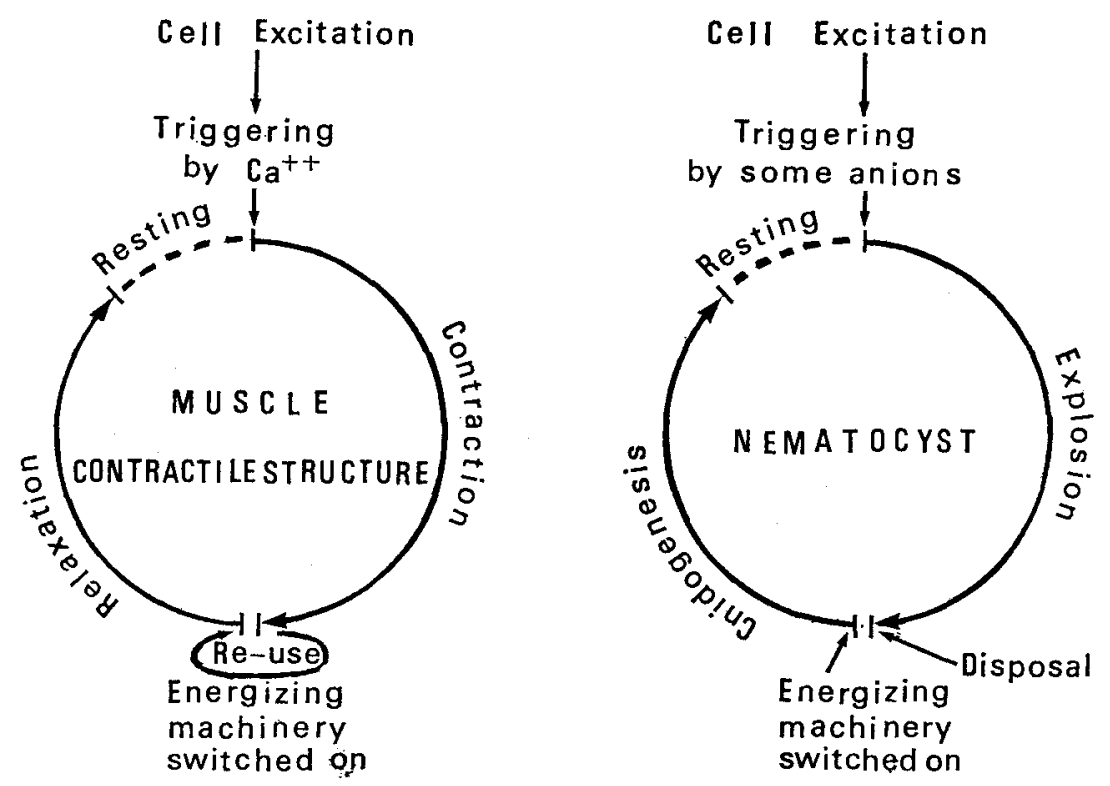

Fig. 8. Diagram to illustrate the "post-energization" view of organelle operation: the cases of muscle contraction and of nematocyst discharge in comparison. 
ATP molecules break down immediately before contraction starts, to release an amount of energy, which acts in turn on the acto-myosin complex to make do work. Postenergization view, on the other hand, understands the resting (relaxed) muscle as corresponding in its energetic state, say, to a rubber string clamped in a position stretched out by an external force. For the contraction to take place, it is only necessary that the trigger is pulled to release energy stored there. As soon as the contraction has finished, the ATP engine is a utomatically put into action in the course of relaxation to stretch again the acto-myosin complex to the elongated (i.e., relaxed) state; therefore post-energization (Fig. 8).

Indeed, at least one of the current standard textbooks (Florey, 1966, p. 567) states that there is no evidence as yet obtained to show that the ATP breakdown in muscle occurs specifically at the contraction phase, rather than the relaxation phase, the situation which majority appears to admit implicitly nowadays. The situation may have been somewhat complicated by intervention of the $\mathrm{Ca}^{2+}$-carrying tubular system ("relaxing factor") which involves another kind of ATP reaction, while it is ATP reaction of the kind immediately responsible for mechanical work of contraction which is in question at present.

A difference between the cnidae and the muscle contractile system is that the former is a disposable tool while the latter is undisposable one to be used repeatedly. One can see the situation in the following way. Both are to be energized prior to use, but not immediately before use. Cnidae are energized in the course of cnidogenesis, about which we are now getting more and more information from the morphological side. Once actually used, the cnidae are pulled out of the surface, say, by the writhing victim or by some releasing act on the cnidarian's side, and thus disposed; it has only to be replaced by a fresh one. Muscles after contraction, on the other hand, are not allowed to be thrown off like this. They are stretched out again at once for re-use, perhaps except in the case of smooth "catch muscles" and the like. And in this process energy is restored; post-energization. The word post-energization itself seems somewhat inappropriate for the case of cnidae; they may better be called to be pre-pre-energized. In a cyclic process like muscle contraction, indeed, pre-preenergization is actually post-energization.

In this sense, the cnidae may be said to be one of the rare examples of triggering event, and a tandem one at that, as freed from all the complicating factors of energy generation and transmission, in this wide world of general and comparative physiology.

\section{The Problem of Nervous Control of Nematocysts}

This paper could not be concluded without mentioning the problem of nervous control of nematocyst discharge, i.e., determinism at the organismal level. In spite of the elaborate drawings of innervated cnidoblasts published by the nineteenth century optical microscopists, cnidoblasts have been supposed to be an independent 
effector functionally since the time of G. H. PARKER, in that an external stimulus could elicit the discharge of those nematocysts only that had been directly hit by that stimulus, without any sign of spreading of the response over the body area, and that no discharge response could be induced by stimulation of some other region of the cnidarian body. On the other hand, there have been a number of findings presented which appeared to suggest a remote control of discharge response. It is a feature in common among such instances of possible control that the control was apparently that in negative sense, i.e., discharge inhibition. The well-known case of fully fed hydras whose tentacle nematocysts would no longer respond to the contact of prey was explained by BURNETT, LENTZ and WARREN (1959) in terms of a certain mechanical effect of the posture taken by such individuals, rather than as a physiological determinism, whereas BoucHET (1961) presented evidence for a really physiological way of control, and, in this symposium, similar evidence was reported by MARISCAL (1973) for two species of sea anemone. The cases in Calliactis attached to a shell and in Stomphia swimming away from a predator are now much reputed, though still remaining as mysteries for all of us as well as for their authors, DavenPort, Ross and Sutton (1961) and Ross and SutTon (1964). ${ }^{4)}$

In the discussion that followed the paper by DAVENPORT (1966) in the 1965 London symposium, Dr. HorRIDGE remarked as follows: “. . . despite careful study of electron micrographs there is at present no evidence that nematocysts are directly innervated. There is nothing to the contrary and at any time we may find a technique for recognition of nerves in such tissues under the electron microscope." Actually, this prediction by HORRIDGe had already been realized at that time in the form of a micrograph showing a "neurite of a neurosecretory cell situated at the base of a cnidoblast" in hydra published by LeNTz and BARRNETT (1965). A few years later, even more convincing pictures for a similar claim were presented by SLAUTTERBACK (1967) and by WestFall (1970) in hydra and in a hydromedusan, though it seems that there is not yet this kind of evidence in an actinian material.

In LENTZ and BARRNETT, there is also physiological evidence produced for participation of nervous element in discharging response, besides the morphological one mentioned above. It is based on their experiments on the effect of acetylcholine and various neuroamines in sensitizing the hydra nematocysts toward mechanical stimulation (LENTZ and BarRneTT, 1962). (see Table 1 of LenTZ, 1966.) It is singular of their case of proposed nervous control (Fig. 9) that the control is in the positive sense, i.e., sensitization. In fact, such a situation seems to have lead WestFall (1970) to extend her discussion of the morphological findings to include a presynaptic inhibition as well as direct excitation of cnidoblast.

All this is the present status of this subject. It would be desirable to find mor-

4) We have also a case of nematocyst control exerted from a symbiont fish in the tentacles of giant anemone (Fukui, 1973). 


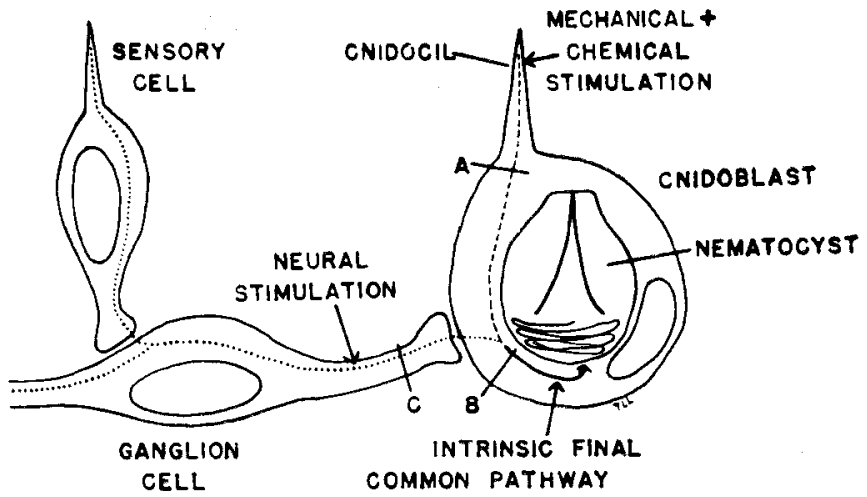

Fig. 9. The mechanism for the control fo nematocyst discharge proposed by LENTz. (After LENTZ, 1966).

phological evidence for the actinian cases of apparent control of discharge and to ensure physiological evidence for the hydrozoan cases of apparent innervation. We may wonder if there is something like nerveless conduction such as revealed by MACKIE and Passano (1968) in hydrozoans to transmit the remote control of nematocysts on the tentacles in these animals as well as in the other groups.

\section{Acknowledgements}

Thanks are due to Mr. Masaki SEKI for cooperation in some recent experiments by the author that have been included in this paper, and also to Mr. Shin-ichi Neмото of the Tateyama Marine Laboratory for his kind help in supply of the material as well as in provision of laboratory facilities.

\section{REFERENCES}

Blanquet, R. 1968. Properties and composition of the nematocyst toxin of the sea anemone, Aiptasia pallida. Comp. Biochem. Physiol 25: 893-902.

— 1970. Ionic effects on discharge of the isolated and in situ nematocysts of the sea anemone, Aiptasia pallida: A possible role of calcium. Comp. Biochem. Physiol. 35: 451-461.

Bouchet, C. 1961. Le controle de la décharge nématocystique chez 1'Hydre. Comptes rend. Acad. Sci. 252: 327-328.

Brien, P. 1961. L'hydre d'eau douce. Brussels.

Burnett, A. L., T. Lentz, and M. Warren 1959. The nematocyst of hydra. I. The question of control of the nematocyst discharge reaction by fully fed hydra. Ann. Soc. Roy. Zool. Belg. 90: $1-21$.

DavenPort, D. 1966. Symbioses and analysis of behavior. In: Rees, W. J. (ed.), "The Cnidaria and their Evolution", pp. 361-372. London: Academic Press.

D. M. Ross, and L. Sutton 1961. The remote control of nematocyst discharge in the attachment of Calliactis parasitica to shell of hermit crabs. Vie et Mil. 12: 197-209.

Florey, E. 1966. "An Introduction to General and Comparative Animal Physiology", p. 567. Philadelphia: W. B. Saunders Co.

FukUI, Y. 1973. Some experiments on the symbiotic association between sea anemone and $\mathrm{Am}$ phiprion. Publ. Seto Mar. Biol. Lab. 20 (Proc. Second Internat. Symp. Cnidaria): 419-430. 
Hyman, L. 1940. "The Invertebrates. Protozoa through Ctenophora", p. 409. New York: McGrawHill.

Lentz, T. L. 1966. "The Cell Biology of Hydra", p. 177. Amsterdam: North-Holland Publ. Co. , and R. J. Barrnetr, 1961. Enzyme histochemistry of hydra. J. Exp. Zool. 147: 125-149. , and R. J. BARRNETT 1962. The effect of enzyme substrates and pharmacological agents on nematocyst discharge. Ibid. 149: 33-38.

- 356.

Mackie, G. O., and L. M. Passano 1968 Epithelial conducton in hydromedusae. J. Gen. Physiol. 52: $600-621$.

Majima, H. 1967. "Seirigaku (Physiology)", 12th ed., p. 63. Tokyo: Bunkodo Publ. Co.

Mariscal, R. N. 1973. The control of nematocyst discharge during feeding by sea anemones. Publ. Seto Mar. Biol. Lab. 20 (Proc. Second Internat. Symp. Cnidaria): 695-702.

Mattern, C. F. T., H. D. Park, and W. A. Daniel 1965. Electron microscope observations on the structure and discharge of the stenotele of hydra. J. Cell Biol. 27: 621-628.

Pantin, C. F. A. 1942. The excitation of nematocysts. J. Exp. Biol. 19: 294-310.

PICKEN, L. E. R. 1953. A note on the nematocysts of Corynactis viridis. Quart. J. Micr. Sci. 94: 203227.

—_ and R. J. Skaer 1966. Review of researches on nematocysts. In: Rees, W. J. (ed.), "The Cnidaria and their Evolution", pp. 19-50. London: Academic Press.

Robson, E. A. 1973. The discharge of nematocysts in relation to properties of the capsule. Publ. Seto Mar. Biol. Lab. 20 (Proc. Second Internat. Symp. Cnidaria): 653-673.

Ross, D. M., and L. SUTTON 1964. Inhibition of the swimming response by food and of nematocyst discharge during swimming in the sea anemone Stomphia coccinea. J. Exp. Biol. 41: 751-757.

Slautterback, D. B, 1967. The cnidoblast-musculoepithelial cell complex in the tentacles of hydra. Zeitschr. Zellf. mikr. Anat. 79: 296-318.

UCHIDA, T. 1929. Studies on the Stauromedusae and Cubomedusae, with special reference to their metamorphosis. Jap. J. Zool., Trans. Abstr. II (2): 103-193.

WeILl, R. F. 1934. Contribution a 1'étude des Cnidaires et de leurs nématocystes. 1. Recherches sur les nématocystes. Trav. St. zool. Wimereux, Tome 10.

Werner, B. 1973. New investigations on systematics and evolution of the class Scyphozoa and the phylum Cnidaria. Publ.Seto Mar. Biol. Lab. 20 (Proc. Second Internat. Symp. Cnidaria): 35-61.

Westfald, J. A. 1965 . Nematocysts of the sea anemone Metridium. Amer. Zool. 5: 377-393. , 1970. The nematocyte complex in a hydromedusan, Gonionemus vertens. Zeitschr. Zellf. mikr. Anat. 110: 457-470.

Yanagita, T. M. 1959a. Physiological mechanism of nematocyst responses in sea-anemone. II. Effects of electrolyte ions upon the nematocysts. J. Fac. Sci. Tokyo Univ., Sect. IV 8: 381-400.

1959b. Do. VII. Extrusion of resting cnidae-its possible bearing on the normal nettling response. J. Exp. Biol. 36: 478-494.

- 1960. Do. III. Excitation and anaesthetization of the nettling response system. Comp. Biochem. Physiol. 1: 123-139.

1969. The response mechanism of nematocysts: the case of freshwater hydra. Bull. Mar. Biol. Sta. Asamushi 13; 221-226.

- 1972. Nematocyst complex as an animal motile system. In: TAmasige, M. (ed.), "Collected abstracts of the results obtained for 1971, Research Group on Experimental Analysis of Excitation and Transmission Mechanisms" (mimeograph, in Japanese).

- and M. SeKr 1973a. The effect of a calcium precipitant salt on the nematocysts from the acontium of sea anemone, Haliplanella luciae. A preliminary note. In preparation. , and 1973b. Electric excitability of nematocysts contained in the hydrothecae of a plumularian, Aglaophenia whiteleggei. Preliminary observations. In preparation.

- , and $1973 \mathrm{c}$. Preliminary experiments on discharge of the nematocysts on the 
tentacles of the cubomedusan, Charybdea rastonii. In preparation.

, and T. WADA, 1959. Physiological mechanism of nematocyst responses in sea-anemone.

VI. A note on the microscopical structure of acontium, with special reference to the situation of cnidae within its surface. Cytologia 24: 81-97.

\section{Appendix}

After the symposium was over and the final manuscript to be submitted had been prepared, the present writer and his collaborator finally succeeded in obtaining steadily a surface membrane potential or "cnidoblast potential" from that side of acontium which is densely beset with nematocysts. Use of finer microelectrodes (less than $1 \mu \mathrm{m}$ )

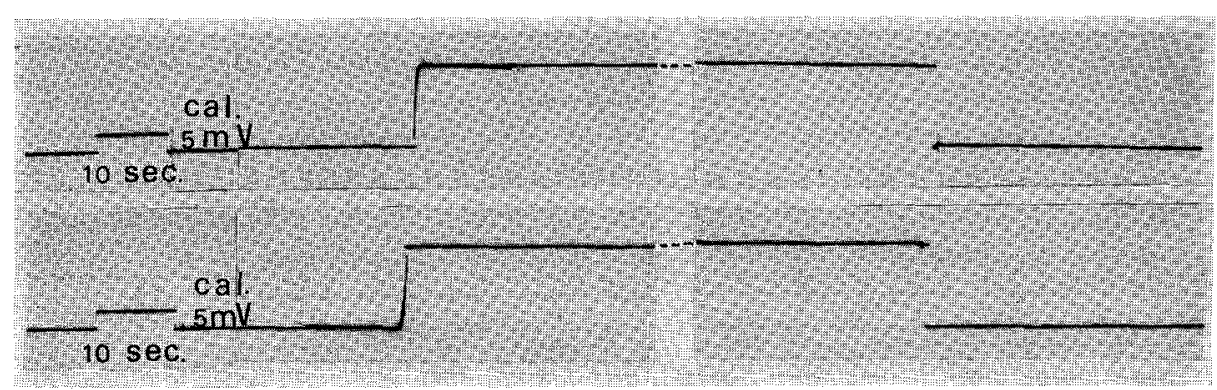

Fig. 10. An oscillograph record of the "cnidoblast potential" from the acontium. It is not yet confirmed whether depolarization made from this potential may lead to nematocyst discharge as the hypothesis would predict.

and control of the depth of insertion seemed to be the cause for this success. The potential (in normal sea water) was quite constant at $-25 \mathrm{mV}$ inside as referred to the outside medium. A sample from the recordings is shown in Fig. 10. 